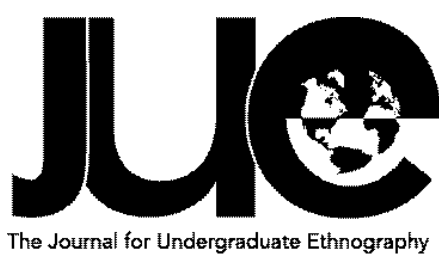

Volume 5 | Issue 1

\title{
Code-Switching in a Multilingual Workplace
}

\section{Alejandra de Socarraz-Novoa}

Saint Louis University_Madrid Campus, alejandradsn@aol.com

\section{ABSTRACT}

his study focuses on code-switching between colleagues in a multicultural and multilingual university workplace environment, focusing solely on the participants' interactions in English and Spanish. Changing languages within one sentence or conversation is referred to as code-switching. Based on earlier studies of code-switching but moving towards a more specific environment, the workplace, this study intends to answer the following two research questions: What form does codeswitching take in the workplace? And, what are the meanings participants assign to the act of code-switching? Using an ethnographic lens, I collected participant observation data and semi-structured interviews with three of the six participants. Analyzing the data through an iterative framework, I identified three distinct meanings that participants assigned to these forms of code-switching: face-saving, expression of raw emotion, and compartmentalization of work and private life.

Keywords: code-switching, multicultural, university workplace 


\section{LITERATURE REVIEW}

Code-switching is an everyday occurrence in multilingual speech communities. "The study of code-switching among members of various language and social communities illuminates how cultural plurality operates in everyday conversation" (Fitch \& Hopper 1983, 116). Existing research on code-switching has focused on who is switching languages, the attitudes different individuals have towards language switching, and its impact on language (i.e. Colón 2002, MacIntyre, Dörnyei, Clément, \& Noels, 1998). On the other hand, literature on language in the workplace focused more on ideology, frame conflict, and discourse struggles, rather than on the act of code-switching itself (i.e., Prego-Vazquez, 2007, Wodak, Krzyżanowski, and Forchtner, 2012). As a result, this study will combine these two approaches to analyze code-switching in a specific university workplace setting.

Language in the Workplace

The workplace as a setting has been the focus of a significant number of studies on language. Researchers have observed language use and language switching between co-workers, as well as employee/customer interactions. Prego-Vazquez's (2007) study identifies the struggles that arise when employees and customers interact. The article focuses specifically on the conflicts that occur when "customers mobilize local discursive patterns, code-switching and conversational topics" (295).

Prego-Vazquez uses critical and sequential analysis, along with sociodiscursive analysis, to approach the study through a multimethod lens. Wodak, Krzyżanowski and Forchtner (2012) analyze the communication that occurs in European Union institutions, specifically instances of multilingual practices. Through the discourse-historical approach, the study finds that although there is a deep sense of power in communication, this power can be overcome, specifically as a result of the multilingualism. Power is manifested in the choice of language, topic, access to the floor, and regulation of interactions. This power and the distribution of it plays a large part in the interactions that occur between multilingual individuals in the European Union.

Attitudes Towards Code-Switching

Investigators have analyzed the meaning behind codeswitching and observed how members of a speech community feel towards these language switches. Fitch and Hopper (1983) focus on attitudes toward code-switching among 45 participat- 
ing students in a multilingual school setting. The meanings attributed to the different choices surrounding language use include: (1) language choice as an inclusion topic, (2) exclusion, and (3) stereotyped attitudes While Fitch and Hopper's research is conducted in a similar setting to mine, the participants in my study are the staff of an office in a multilingual, multicultural university, and the focus of this research is on the meaning attributed to the language switches themselves, rather than on the attitudes the members take in doing their code-switching.

Effects of Code-Switching on Language

Other studies have focused on the effects code-switching can have on language understanding and comprehension. $\mathrm{Lu}$ (2014) hypothesizes that if a person cannot express themselves completely in one language, it means that the person does not completely understand the language. Lu's study shows that code-switching occurs above all when one is speaking in one's second language. The study also found that the participants did not think that code-switching was detrimental to language competence. MacIntyre, Dörnyei, Clément, and Noels (1998) studied second language use: when the second language was used and why. There were two main goals for the study. First, they identified all accounts of psychological, communicative, and linguistic behavior that could potentially affect communication. Second, they tried to find relationships between these behaviors in order to outline a model that would help predict, describe, and explain communication when using a second language. Their findings indicated that anxious students did not communicate as thoroughly in the second language, which caused a negative correlation in the results of their proficiency.

Code-switching is a regular occurrence in a multicultural and globalized society. There are many situations in which individuals find themselves switching between two languages. As mentioned previously, most research focuses on language in the workplace, the meaning of language, and the effects of multilingualism. However, research should focus on all the different aspects of code-switching, particularly on the meanings given by members of the speech community, in the context of that community. Whether meanings of code-switching in the workplace have positive aspects or not, communication between members of a multilingual speech community has distinctive patterns. Therefore, the goal of this study is to observe and analyze the meanings of code-switching in a multicultural workplace setting. My research questions are the following: What forms does code-switching take in the workplace? What are the meanings that participants in a workplace setting attribute to code-switching?

\section{METHODS}

Participants

In my formal investigation, six members of a multicultural, multilingual university workplace environment participated in the study. The six members include: K.G. and H.B., both from the United States (Connecticut and Pennsylvania respectively); M.C., from Venezuela, D.R., from Spain, K.M., from Algeria, and B.M., from the Philippines. The members of the speech community work in the admissions department of an American university in Spain. All interactions between the participants and myself were exclusively in English and Spanish, although some of the participants spoke more than two languages. I use first name and last name initial to protect the identity of the participants in the study.

Data Collection

Due to my personal affiliation with the members of this speech community (as a part-time, student worker in the office), I conducted participant observations as a focused participant observer, which refers to "an observer who enters a scene with an explicit researcher status and a clear agenda of what data to gather in the scene" (Tracy 2013, 111-112). Observations were followed with ethnographic interviews with three of the six participants. An "ethnographic interview is a conversation that is specifically instigated by the researcher and may not have occurred otherwise" (140). Based on the initial data, I determined who were to be the interviewees by looking at my data and choosing the members who were most involved in the act of code-switching. According to Tracy (2013), "structured interviews without long-term participation are a common method of data collection for focused participant observers" (112). All interviews were conducted individually and lasted between 10 and 20 minutes. Interview questions were based on the data gathered in the previous observations and incorporated examples of code-switching that I had observed firsthand. Specific anecdotes, phrases, and words that were mentioned in previous interviews were also taken into account and included in interviews with other participants. All three interviews were 
conducted in English - the primary language of the university-in the conference room of the admissions department at the university. The interviews were recorded on camera and subsequently transcribed.

Analytic Procedure

In the process of analyzing the data collected through participant observation and ethnographic interviews, the pragmatic iterative approach was utilized. The pragmatic iterative approach, coined by Tracy (2013), combines emic and etic interpretations (that is, observer and native meanings) of practices. This framework encourages the researcher not only to analyze the data through an emic approach but also to look into "the active interests, current literature, granted priorities, and various theories the researcher brings to the data" (184), as well as taking into account participants' perspectives. As Srivastava \& Hopwood (2009) state, iteration is not an automatic task, but intends the researcher to reflect on the data throughout the process. The researcher "visits and revisits the data, connects them to emerging insights, and progressively refines his/ her focus and understandings" (Tracy 2013, 184). Following the steps employed by this framework, I identified codes in the data collected through participant observation. First-level coding determined all instances of code-switching among the six participants in the workplace setting. "First-level codes focus on 'what' is present in the data. They are descriptive, showing the basic activities and processes in the data" (Tracy 2013, 189). Second-level codes were determined by a two-step method: first, classifying code-switching instances into meanings determined by the researcher, i.e. me. "Second-level codes serve to explain, theorize, and synthesize them. Second-level coding includes interpretation and identifying patterns, rules, or cause-effect progressions" (Tracy 2013, 194). Finally, the interviews provided an understanding of the native speakers' point of view, adjusting the initial meanings I had assigned to the code-switching acts identified.
FINDINGS

Three principal meanings of code-switching were identified within this particular speech community: face-saving, expression of raw emotion, and compartmentalization of work and private life. In the following sections, I will present concrete instances of code-switching that illustrate these meanings together with commentary from participants that elaborates on them.

Face-saving

Face-saving, according to Trenholm (2011), is when politeness is used for more than just a social nicety, but instead in a way that acknowledges others identities and, consequently, saves face. "Face is the 'conception of self that each person displays in particular interactions with others"' (138). The first data analyzed involved an external participant in the speech community. The external member, M.M., is not immediately in this workplace speech community but resides on the edge because of her position as head of the department. In the months observed, M.M. had three group meetings with all six of the participants, and there was only one instance where one participant was missing due to the fact that she was out of town. One field note obtained an instance of code-switching that occurred due to M.M..

All participants were at work and tentatively awaiting M.M. for a meeting that was to take place at 12:30. H.B. and K.G. were conversing in English about student applications when M.M. walked in. They immediately directed conversation to M.M. in Spanish and stopped talking amongst each other. All seven participants walked towards the back of the room where there is a small conference table. The entire conversation proceeded in Spanish and the topic of the meeting was, among other things, arranging vacation dates. When K.G. directed a question or comment to H.B. she spoke in Spanish, with the exception of one word, "planning," which she pronounced with a Spanish accent.

When first analyzing this data through second-level coding, I believed that M.M.'s power and authority were the explanation and, consequently, the meaning for the language change. The infrequent use of code-switching or immediate switch from English to Spanish in the speech community when M.M. would gather the participants for meetings led me to this conclusion. When interviewing two of the three participants, however, they 
expressed different thoughts and meanings about the situation. They assured me that the relationship was not one of power but rather of equality.

H.B.: I only ever speak Spanish with M.M., unless there's someone who speaks poorer Spanish in the conversation, then we speak in English. I think she prefers to speak Spanish... I think it's really a close relationship. I don't think she's like a super authority figure. I think the levels here are pretty close. I always e-mail her in Spanish. I think it's based on how well the other person speaks.

After obtaining the research participants' meanings, I realized that they viewed this situation as one of face-saving for M.M.. They identified that M.M. does not feel comfortable or confident in her proficiency of English; consequently they felt obligated to speak Spanish exclusively around her. It appears that, although the participants denied that code-switching did take place because of the power M.M. holds, I believe it still might be a prominent factor in the situation. It is also possible that the participants understood power as something concrete, i.e., "being above us" rather than something abstract, as in influence. K.G. agreed that M.M.s position and power affected the language and the way in which she spoke to M.M.. "I'm conscious about not putting in words in English when I'm speaking in Spanish in front of her because she's my boss... I try not to in front of M.M. because she doesn't like it. And yeah, she's the boss." Since participants had different views and meanings of the situation, I directly asked M.M. what she thought about her position. "We are a team. I don't feel like I have any power and I do not want to have any power."

Expression of raw emotion

Raw emotion refers to the person's instinctual reaction to any given situation, specifically focusing on verbal displays. There were various instances where code-switching of this kind occurred, but one telling circumstance was when participants felt disrespected by P.M., another person external to the speech community (although it should be noted that situations of this kind can and do happen between the members themselves as well).

P.M. walks into the admissions department asking for K.M. who is not present. When she realizes K.M. is not there, she directs conversation at the rest of the participants asking if anyone knows where she can send a recommendation letter that is past its due date. All participants consult each other to see if anyone knows but no one is sure what to do and how to send the letter. At this point, P.M. becomes upset and makes a sassy comment to the participants. H.B. responds to P.M.'s comment stating "It's like if we were to ask you an English question, P.M., and you're a science teacher." It is suggested by one of the participants that P.M. go up to the registrar's office to see if she can sort out her dilemma there. As soon as P.M. leaves, the participants burst out with comments of what just happened in their native languages. Due to everyone speaking at the same time, I was only able to catch what D.R. had said, "Que morro tiene" ("Oh, what nerve").

Code-switching in this case is used as an instinctive mode of expression. The term coined for the meaning given was taken from K.G.s statement during her interview: "When you're expressing raw emotion... 'cause it's sort of almost like an instinct... like when you drop something or when something totally surprises you, it comes out in your native language." Emotions are expressed in your first language because that is the way in which you first learn to express yourself whether you are feeling angry, surprised, or happy. Another instance where this occurred was when H.B. began singing the Fresh Prince of Bel Air song and M.C. commented "Ay, que bueno" (that's a good one). They are spontaneous expressions and emotions that are difficult to translate. Expressions of emotions tend to be delivered in idioms. An idiom carries specific meaning and when translated into one second's language it is not as accurate, even if a corresponding idiom exists in the second language.

Compartmentalization of work and private life

Code-switching of words, phrases, or conversation, in general, constantly took place between the participants. Patterns emerged when participants would communicate about work and their private life. Because of the university's American-centered education, most, if not all conversations having to do with students, databases and operating systems such as the 'Banner' system, etc. tended to be conducted in English. On the other hand, conversations about private life were almost exclusively conducted in Spanish because all the participants' at-home lives are in Spanish. During all three interviews conducted, the participants stated that words exclusive to the university and work that they do at the university are always said in English. 
K.G.: Some of the words that we use, for example in Banner, like 'withdraw', I don't know how we really say that in Spanish, una baja I guess but... words that I think that I use specifically in English are 'transcript', I guess because it is an English concept for me more. I know that there's a word in Spanish, expediente, which I could use but I never do.

'Transcript' I always say in English, and hold on a second I had one a second ago, what was it? Shoot. There was another word, oh, 'report.' 'Cause we can do reports in the database and I always say, 'hago un report'. But, I understand that word is in English.

The participants are aware that the words exist in the other language but, as K.G. stated, they seem to be English concepts. According to K.G., it is enough to know these "workplace" words and phrases in one language. Especially when all the members of the speech community understand this common work language, there is no need to translate or adjust these concepts. While observing the participants and during all three interviews, the participants agreed with K.G.s statement above: that words and phrases having to do with work or work operating systems such as Banner were always in English. Personal life, on the other hand, was discussed primarily in Spanish. The following instance demonstrates an example of code-switching when speaking of personal life. K.G. is talking to K.M. and D.R. about how her daughter has had a bleeding rash for a few days. K.G. feels guilty about her daughter's rash because she Googled it and believes that the rash has been in part caused by the amount of strawberries that she has been giving her daughters lately.

D.R.: No es nada de desinterés, es tu culpa? (It's not because you are not interested, is it your fault?)

K.G.: No, la de las fresas. (No, the strawberries.)

D.R.: Y otra cosa... nunca hagas consultas médicas for

Google. (And another thing... don't consult medical issues on Google.)

There are code-switches occurring throughout the conversation but, the core language that is guiding the conversation is Spanish because K.G. is speaking about a personal situation she is experiencing with her child. This instance also demonstrates the second meaning applied to code-switching, expression of raw emotion, on D.R.'s part, who is comforting K.G. in his native language, Spanish. Another instance where code-switching on account of personal life was when H.B. directed conversation at me in English stating that she had gone to the pelu (hairdresser) and the ceiling was goteando (leaking). In this instance she is code-switching between English and Spanish, but the two words that she is speaking in Spanish are exclusive to a situation that occurred in her private life. Situations that occur in the personal life have to be dealt with in Spanish, therefore, when reported, they are spoken in Spanish. Living in Madrid and athome life being spoken in Spanish makes it difficult to transmit and translate these situations, especially when it is common knowledge that all members speak both English and Spanish. 


\section{CONCLUSION}

This study gives valuable insight on the meaning of codeswitching by members of a multicultural workplace environment. It is very telling on the meanings that participants give different situations that arise at work. The three meanings that arose from studying these participants illustrate unspoken norms of when code-switching should or should not occur. In particular, it appears to be significant in relation to the aspect of personal relationships within the workplace. Individuals working together will "honor" the primary language of communication between the parties. However, if a new person enters the conversation, the language will change according to who that person is, what role he or she plays within the workplace, and what is his or her language of preference. An example of this was evidenced by my observation of face-saving and power relations in M.M.. Another important observation and implication of my study was how code-switching contributed to a healthy workplace. By this I mean an environment that takes into account the differences between people, specifically linguistically. Code-switching can, in fact, be a clear representation of respect for these differences and other significant social cues (i.e. roles, language competence, language preference). The phenomenon of code-switching is more prevalent as groups of people from around the world work together in a shared place. As globalization increases, the amount of code-switching will increase and more meanings will be created across diverse groups.

This study was limited by time constraints and lack of opportunity for complete full-time immersion in the speech community. Future research should study various multicultural and multilingual groups, in order to obtain and compare more data. Also, future researchers should try to incorporate themselves more into the speech community. I was unable to achieve full participation in the speech community because I am a student worker and consequently much younger than the participants. Future researchers should also try to record during participant observation. There were many times when participants would all speak at once and it almost became impossible to cite anything they said verbatim. Taking into account these findings, limits and goals, as more research is done future researchers will find more meanings and gain better understanding of codeswitching in a multicultural workplace environment. 


\section{REFERENCES}

Colón, Mark. 2002. "Line Drawing, Code Switching, and Spanish as Second-Hand Smoke: English-Only Workplace Rules and Bilingual Employees." Yale Law \& Policy Review 20: 227261. http://www.jstor.org/stable/41308521

Fitch, Kristine and Robert Hopper. 1983. "If You Speak English They'll Think You're a German: Attitudes Toward Language Choice in Multilingual Environments." Journal of Multilingual and Multicultural Development 4: 115-127.

Lu, Dan. 2014. "Code-mixing and its impact on language competence." International Journal of Language Studies 8: 75-90.

Maclntyre, Dörnyei, Clément, and Kimberly A. Noels. 1998. “Conceptualizing Willingness to Communicate in a L2: A Situational Model of L2 Confidence and Affiliation." The Modern Language Journa/82: 545-562. http://www.jstor.org/stable/330224

Parr, Bracey Hong 2013. "Baby, te amo": Code Switching as a Way to Develop and Limit Intimacy in Multilingual, Romantic Relationships. The Journal of Undergraduate Ethnography 3:12-22.

Prego-Vazquez, Gabriela. 2007. "Frame conflict and social inequality in the workplace: professional and local discourse struggles in employee/customer interactions." Discourse Society 18: 295-335. http://das.sagepub.com/content/18/3/295

Saville-Troike, Muriel. 2003. The Ethnography of Communication: An Introduction. Malden, MA: Wiley-Blackwell.

Tracy, Sarah J. 2013. Qualitative research methods: Collecting evidence, crafting analysis, communicating impact. Malden, MA: Wiley-Blackwell.

Trenholm, Sarah. 2011. Thinking through Communication"An Introduction to the Study of Human Communication. Boston: Allyn \& Bacon.

Wodak, Krzyżanowski, and Bernhard Forchtner. 2012. “The interplay of language ideologies and contextual cues in multilingual interactions: Language choice and code-switching in European Union institutions." Language in Society 41: 157-186. http://www.jstor.org/ stable/41487752

This work is licensed under a Creative Commons AttributionNonCommercial-

NoDerivs 3.0

Unported License. 